\title{
PRODUÇÃO DE UMA MOLÉCULA RECOMBINANTE HÍBRIDA DE DUAS PROTEÍNAS DE Streptococcus pneumoniae: PspA94-PdT
}

\author{
S. Kraschowetz ${ }^{1}$, D. B. Figueiredo ${ }^{1}$, G. Campani $\mathrm{Jr}^{2}$, G. G. Silva ${ }^{2}$, T. C. Zangirolami ${ }^{2}$, L. C. \\ C. Leite $^{1}$, J. Cabrera-Crespo ${ }^{1}$, V. M. Gonçalves ${ }^{1}$ \\ ${ }^{1}$ Instituto Butantan, Centro de Biotecnologia, Laboratório de Bioprocessos \\ ${ }^{2}$ Universidade Federal de São Carlos, Departamento de Engenharia Química \\ E-mail para contato: stefanie@usp.br
}

\begin{abstract}
RESUMO - A baixa cobertura em termos de sorotipos das vacinas atuais contra $S$. pneumoniae tem levado à busca por novos antígenos que ofereçam proteção independente de sorotipos. Assim, este trabalho propõe a produção de um híbrido das proteínas PspA e pneumolisina geneticamente detoxificada, que mostrou-se imunogênico e protetor em camundongos. Para isso a molécula foi obtida em $E$. coli com cauda de histidina. Os cultivos foram realizados em reator de $5 \mathrm{~L}$ e a purificação seguiu as seguintes etapas: ruptura celular em homogeneizador contínuo de alta pressão, precipitação com detergente catiônico CTAB, clarificação, cromatografia de troca aniônica e cromatografia de interação hidrofóbica, alcançando $85 \%$ de pureza e recuperação de $4 \%$. A baixa recuperação ocorreu porque o híbrido mostrou-se instável.Duas bandas principais foram observadas na eletroforese, que correspondiam a cada uma das proteínas do híbrido, tal como revelado por Western Blot. Novas construções de híbridos estão sendo elaboradas com espaçadores rígido e flexível a fim de aumentar sua estabilidade.
\end{abstract}

\section{INTRODUÇÃO}

O Streptococcus pneumoniae é a causa de várias doenças tais como pneumonia, otite, sinusite, meningite e sepse. Essas doenças invasivas matam 1,6 milhões de pessoas no mundo a cada ano, sendo que a maior parte desses óbitos ocorre em países subdesenvolvidos (World Health Organization, 2007). As vacinas atualmente existentes no mercado baseiam-se o polissacarídeo capsular (PS), livre ou conjugado a uma proteína, mas o seu elevado custo de produção não permite a sua distribuição para toda a população afetada. Além disso, as vacinas disponíveis no Brasil não cobrem todos os casos de doença pneumocócica invasiva no país. A fim de reduzir o custo e aumentar a cobertura da vacina pneumocócica, tem sido proposta a produção de uma nova vacina conjugada, incluindo os sorotipos de PS prevalentes ligados a proteínas de pneumococos. Entre as proteínas estudadas, a proteína de superfície de pneumococo (PspA) e pneumolisina (Ply) demonstraram os resultados mais promissores no modelo de sepse e o uso combinado destas duas proteínas fusionadas geneticamente mostrou o maior potencial de proteção contra o desafio sistêmico em ratos (Goulart, 2013). Devido à sua toxicidade, Ply foi geneticamente detoxificada (PdT) para ser incluída na vacina (Berry, 1995). 


\section{OBJETIVOS}

Produzir e purificar proteínas recombinantes híbridas de PspA e PdT com ou sem espaçadores entre elas.

\section{MATERIAIS E MÉTODOS}

Os cultivos foram realizados utilizando a cepa de E. coli M15 contendo o plasmídeo pQE30 + PspA94-PdT, nesta construção as duas proteínas do híbrido encontram-se justapostas, sem qualquer sequência espaçadora entre elas, e o híbrido é produzido com uma cauda de histidina N-terminal. Os cultivos em biorreatores foram realizados pela equipe do LaDaBio, UFSCar, sob orientação da Profa. Dra. Teresa Cristina Zangirolami.

\subsection{Purificação da proteína híbrida PspA94-PdT}

A PspA94-PdT foi produzida intracelularmente e, por este motivo, as células foram centrifugadas para remover o meio de cultura e armazenadas a $-80^{\circ} \mathrm{C}$ até a extração. Para extração, as células foram primeiramente descongeladas $\left(4^{\circ} \mathrm{C}\right)$ e ressuspendidas no tampão de lise na relação de $100 \mathrm{~g}$ de biomassa úmida para $1 \mathrm{~L}$ de tampão de lise (tampão fosfato $10 \mathrm{mM}$ pH 6,5 + 1mM EDTA + 1mM PMSF + 0,1\% Triton) com a ajuda de um mixer.

A extração foi feita em homogeneizador contínuo de alta pressão (APV Gaulin), com um trocador de calor casco-tubo na saída e um reservatório dotado de camisa de resfriamento na entrada, ambos para controle da temperatura. Fixando-se a pressão e a temperatura, o tempo ideal para ruptura foi determinado através da quantificação de células lisadas e proteína liberada por tempo.

Após a homogeneização, foi realizada a clarificação através de adição do detergente catiônico brometo de cetiltrimetilamônio (CTAB , Sigma), centrifugação e filtração a vácuo. A concentração ótima de CTAB a ser adicionada foi determinada em testes visuais de leitosidade do homogenato. A concentração escolhida, que precipitou mais impurezas sem acarretar grandes perdas da proteína em interesse, foi a maior concentração que ainda apresentou leitosidade no sobrenadante. Após adição de CTAB, a centrifugação foi realizada por $2 \mathrm{~h} \mathrm{a} 4^{\circ} \mathrm{C}$ e $16.696 \mathrm{~g}$ e a filtração a vácuo com membrana de poros de $0,45 \mu \mathrm{m}$.

O material clarificado foi então submetido a etapas cromatográficas. Cromatografias de troca iônica (Q-Sepharose Fast Flow, GE HealthCare), interação hidrofóbica (PhenylSepharose Fast Flow HighSub, GE HealthCare) e afinidade por metal (IMAC-Sepharose 6 Fast Flow, GE HealthCare) foram testadas de forma a maximizar o rendimento e a pureza do processo.

\subsection{Ensaio de atividade proteolítica e integridade da PspA94-PdT}

O ensaio de atividade proteolítica nas amostras da purificação foi efetuado utilizando-se como substrato solução de caseína $10 \mathrm{mg} / \mathrm{mL}$ em tampão tris $20 \mathrm{mM}$ pH 8 contendo $0,02 \%$ de azida sódica. A caseína não hidrolisada foi precipitada com ácido tricloroacético (TCA) na concentração final de $10 \%$ e a absorbância a $280 \mathrm{~nm}$ do sobrenadante foi medida imediatamente (brancos) e após $48 \mathrm{~h}$ de incubação a $37^{\circ} \mathrm{C}$. Foram empregados um controle 
positivo com tripsina $0,5 \mathrm{mg} / \mathrm{mL}$ e um controle negativo com água destilada no lugar das amostras (Gonçalves, 2003).

A integridade da PspA94-PdT foi verificada por eletroforese (SDS-PAGE 10\%) das amostras logo após cada etapa da purificação e depois de mantidas a $4^{\circ} \mathrm{C}$ por 15 dias. Além disso, Western Blot foi feito com anticorpos contra ambas as proteínas que constituem o híbrido, obtidos pela imunização de camundongos com cada uma das proteínas recombinantes isoladamente, além de um soro de coelho imunizado com extrato total de pneumococo, que contém anticorpos contra as duas proteínas nativas.

\subsection{Construção da proteína híbrida com espaçadores}

Para a clonagem do híbrido com espaçador entre as duas proteínas foi utilizada a técnica de overlap extension PCR. Para isso primers foram desenhados de modo a inserir uma região (o linker) entre as duas cadeias polipeptídicas da proteína híbrida (Hoa, 1988).

Dois tipos de primers foram desenhados: um para inserir um espaçador rígido que forma uma alfa-helice e já foi utilizado com sucesso para separação de domínios de proteínas fusionadas (Arai, 2001 e 2004, 2001; Lee, 2013); outro para inserir um espaçador flexível, composto de glicinas e serinas (Chichili, 2012; Chen, 2013). Os primers foram desenhados com a ajuda da calculadora de temperatura de melting e annealing online da New England Biolabs (New England Biolabs, 2014).

O produto do overlap extension PCR, o gene pspA94-pdt com linker, será inserido num vetor de clonagem pGEM-T easy vector (Promega). Células competentes de E. coli DH5a serão transformadas com esse plasmídeo. Posteriormente, o vetor de clonagem será digerido com as enzimas de restrição NcoI e XhoI e religado em vetor de expressão pET-28a (Novagen), inseridos em uma linhagem de E. coli de expressão.

\subsection{Metodologia Analítica}

O metodo de Lowry foi utilizado para determinar a concentração de proteínas empregando albumina do soro bovino (BSA) como padrão (Lowry et al., 1951).

A pureza relativa de PspA94-PdT foi determinada por densitometria dos géis de SDSPAGE. Tabelas de purificação foram construídas para avaliar e orientar os processos contendo os seguintes parâmetros: proteína total por etapa, quantidade de PspA94-PdT por etapa, recuperação global e por etapa, pureza relativa e fator de purificação global e por etapa.

Os produtos de PCR foram analisados através de eletroforese em gel de agarose $1 \%$. As bandas do gel foram purificadas utilizando-se kit de purificação GFX PCR DNA and Gel Band Purification Kit, e a purificação de DNA foi feita com kit de purificação Illustra plasmidPrep Mini Spin Kit (ambos da GE Healthcare).

\section{RESULTADOS}

\subsection{Purificação 1}

No processo de purificação 01, o tempo ótimo de lise foi de 6 minutos (Figura 1) e a concentração de CTAB escolhida para a etapa de precipitação de impurezas foi de $0,35 \%$. 
Essa escolha foi feita após 30 min do início da sedimentação do precipitado, porém verificouse após 24 h que a concentração de CTAB mais conveniente seria a de 0,25\% (Figura 2).

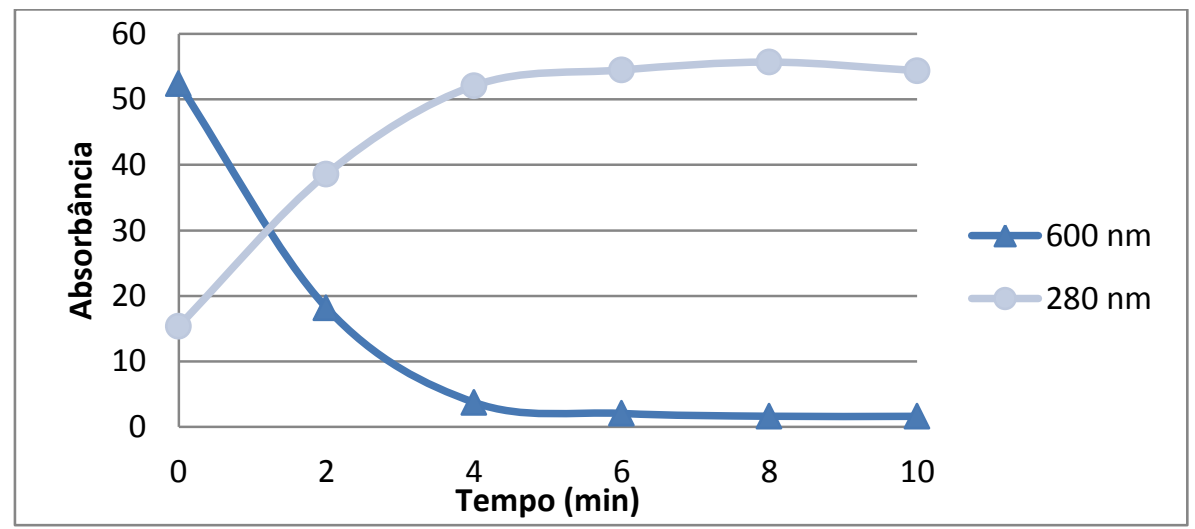

Figura 1 - Lise das células (Abs 600nm) e liberação de proteínas (Abs 280nm) do processo de purificação 01

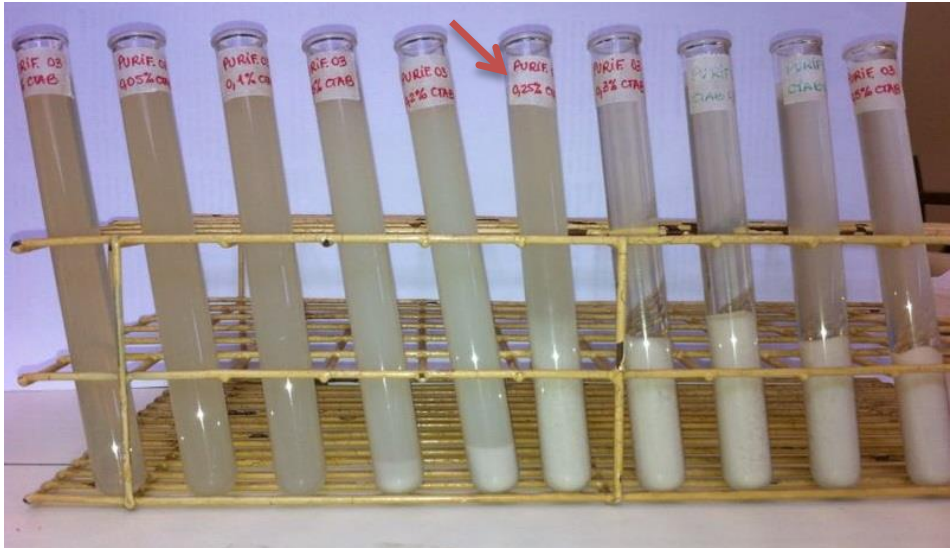

Figura 2 - Teste de precipitação de impurezas com CTAB do processo de purificação 01.

A flecha indica da concentração de $0,25 \%$

A pureza ao final deste processo foi de $86,2 \%$ (Tabela 1). A recuperação das etapas cromatográficas foi bem menor que o esperado, quando comparadas a recuperações de processos de purificação de outras proteínas recombinantes onde a PspA não está fusionada à PdT, como a PspA4pro (Figueiredo, 2013) e a PspA3 (Carvalho, 2009).

Tabela 1 - Processo de purificação 01

\begin{tabular}{|c|c|c|c|c|c|c|}
\hline Amostra & $\begin{array}{c}\text { Pureza } \\
\text { PspA94- } \\
\text { PdT }(\%)\end{array}$ & $\begin{array}{c}\text { PspA94- } \\
\text { PdT Total } \\
(\mathrm{mg})\end{array}$ & $\begin{array}{c}\text { Recuperação } \\
\text { PspA94-PdT } \\
\text { (Absoluta, \%) }\end{array}$ & $\begin{array}{c}\text { Recuperação } \\
\text { PspA94-PdT } \\
\text { (Etapa, \%) }\end{array}$ & $\begin{array}{c}\text { Fator de } \\
\text { Purificação } \\
\text { Absoluto }\end{array}$ & $\begin{array}{c}\text { Fator de } \\
\text { Purificação } \\
\text { Etapa }\end{array}$ \\
\hline Homogenato & 9,1 & 1363,40 & 100,0 & 100,0 & 1,0 & 1,0 \\
\hline $\begin{array}{c}\text { Clarificado com } \\
0,35 \% \text { CTAB }\end{array}$ & 14,2 & 696,54 & 51,1 & 51,1 & 1,6 & 1,6 \\
\hline $\begin{array}{c}\text { F3 Q 200mM } \\
\text { NaCl }\end{array}$ & 48,5 & 472,77 & 34,7 & 67,9 & 5,3 & 3,4 \\
\hline $\begin{array}{c}\text { F3 IMAC 250mM } \\
\text { imidazol }\end{array}$ & 86,2 & 121,82 & 8,9 & 25,8 & 9,5 & 1,8 \\
\hline
\end{tabular}

\subsection{Purificação 2}


No processo de purificação 02, o tempo ótimo de lise foi de $8 \mathrm{~min}$ (Figura 3) e a concentração de CTAB escolhida para a etapa de precipitação de impurezas foi de $0,10 \%$. Neste teste de precipitação de impurezas com CTAB, as amostras foram centrifugadas a $10.000 \mathrm{rpm}$ por $10 \mathrm{~min}$ antes do exame visual de leitosidade.

A recuperação das etapas cromatográficas deste processo também ficou muito aquém do esperado (Tabela 2), assim como no processo de purificação 01, por isso, a hipótese de que a proteína estaria sendo degradada durante o processo de purificação passou a ser investigada por meio dos ensaios de atividade proteolítica e Western Blot.

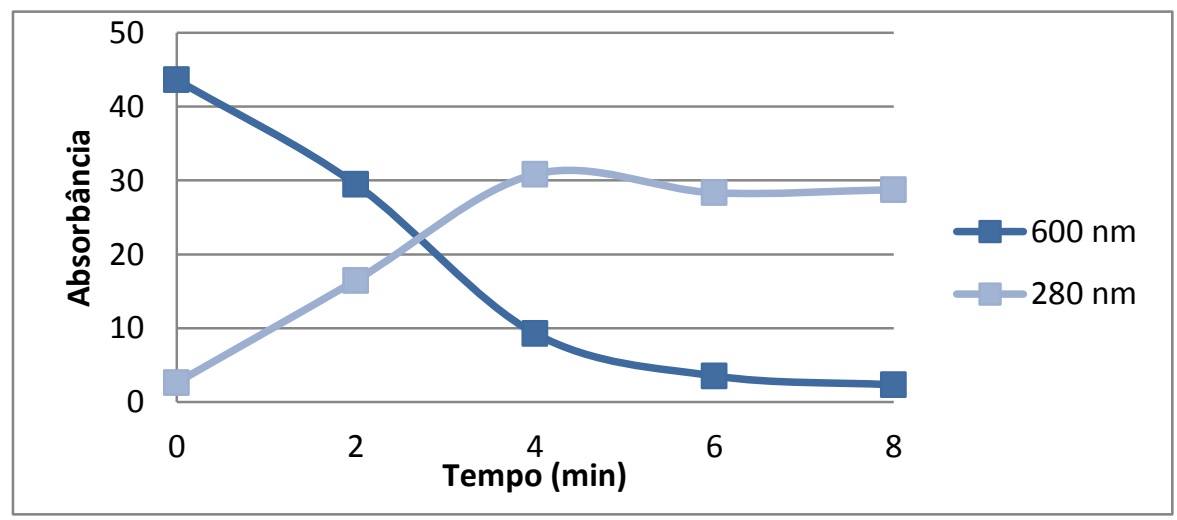

Figura 3 - Lise das células (Abs 600nm) e liberação de proteínas (Abs 280nm) do processo de purificação 02

Tabela 2 - Processo de purificação 02

\begin{tabular}{|c|c|c|c|c|c|c|}
\hline Amostra & $\begin{array}{c}\text { Pureza } \\
\text { PspA94- } \\
\text { PdT (\%) }\end{array}$ & $\begin{array}{c}\text { PspA94- } \\
\text { PdT Total } \\
(\mathrm{mg})\end{array}$ & $\begin{array}{c}\text { Recuperação } \\
\text { PspA94-PdT } \\
\text { (Absoluta, \%) }\end{array}$ & $\begin{array}{c}\text { Recuperação } \\
\text { PspA94-PdT } \\
\text { (Etapa, \%) }\end{array}$ & $\begin{array}{c}\text { Fator de } \\
\text { Purificação } \\
\text { Absoluto }\end{array}$ & $\begin{array}{c}\text { Fator de } \\
\text { Purificação } \\
\text { Etapa }\end{array}$ \\
\hline Homogenato & 25,0 & 8535,6 & 100,0 & 100,0 & 1,0 & 1,0 \\
\hline $\begin{array}{c}\text { Clarificado com } \\
\text { 0,10\% CTAB }\end{array}$ & 40,6 & 6171,3 & 72,3 & 72,3 & 1,6 & 1,6 \\
\hline $\begin{array}{c}\text { F3 Q 200mM } \\
\text { NaCl }\end{array}$ & 54,0 & 3015,1 & 48,7 & 67,4 & 2,2 & 1,3 \\
\hline $\begin{array}{c}\text { F2 Phenyl } \\
\text { 400mM NaCl }\end{array}$ & 85,5 & 126,7 & 3,6 & 7,4 & 3,4 & 1,8 \\
\hline
\end{tabular}

\subsection{Ensaio de atividade proteolítica e integridade da PspA94-PdT}

Evidência da degradação da proteína: A degradação da proteína foi verificada através de eletroforese SDS-PAGE de amostra da purificação 02 após armazenagem por 15 dias a $4^{\circ} \mathrm{C}$ (Figura 4).

Ensaio de atividade proteolítica: Duas amostras eluídas da cromatografia hidrofóbica, Phenyl F2 e F3, provenientes do processo de purificação 02 foram avaliadas quanto à presença de atividade proteolítica, e o resultado foi negativo para ambas, enquanto o controle positivo contendo tripsina apresentou elevada absorbância a $280 \mathrm{~nm}$ (Figura 5). 


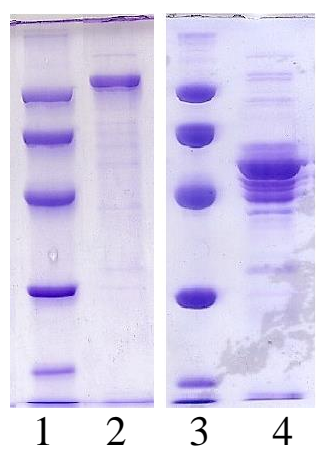

Figura 4. SDS-PAGE da fração Phenyl F2 imediatamente após purificação (canaleta 2) e após armazenagem (canaleta 4), padrão de PM (canaletas 1 e 3: 97, 66, 45, 30 e 20 kDa)

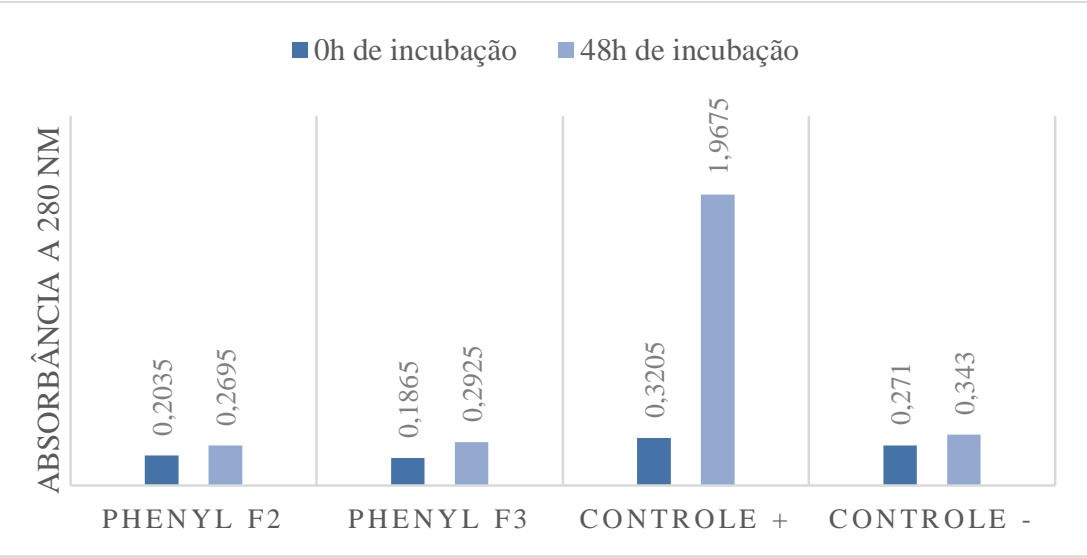

Figura 5 - Ensaio de atividade proteolítica de amostras do processo de purificação 02

Western Blot: Uma vez que não foi encontrada atividade proteolítica nas amostras da purificação, procedeu-se com a análise da degradação da proteína híbrida por Western Blott. A Figura 6 mostra que a fatia central da membrana, tratada com soro de extrato total de pneumococo revelou as bandas da PspA94 e da PdT separadas uma da outra, ou seja, a proteina híbrida está sofrendo quebra entre as duas moléculas unidas geneticamente nesta construção.

\subsection{Nova construção do híbrido com espaçador rígido}

Visando solucionar o problema de estabilidade do híbrido, que está quebrando entre a PspA94 e a PdT (Figura 6), foi elaborada uma estratégia para construção de novos híbridos incluindo espaçadores entre as duas proteínas.. Além disso, a última região rica em prolina da PspA94 foi removida dessa nova construção, o que deverá acarretar maior estabilidade, já que moléculas recombinantes estáveis já purificadas em nosso laboratório, como a PspA4pro e a PspA3, foram clonadas sem essa região (Moreno, 2010).

O linker rígido utilizado foi: 5'A(EAAAK) 3 A 3' (Lee, 2012; Chen, 2012) e os primers desenhados para realizar as reações de overlap extension PCR estão mostrados na Tabela 3. 

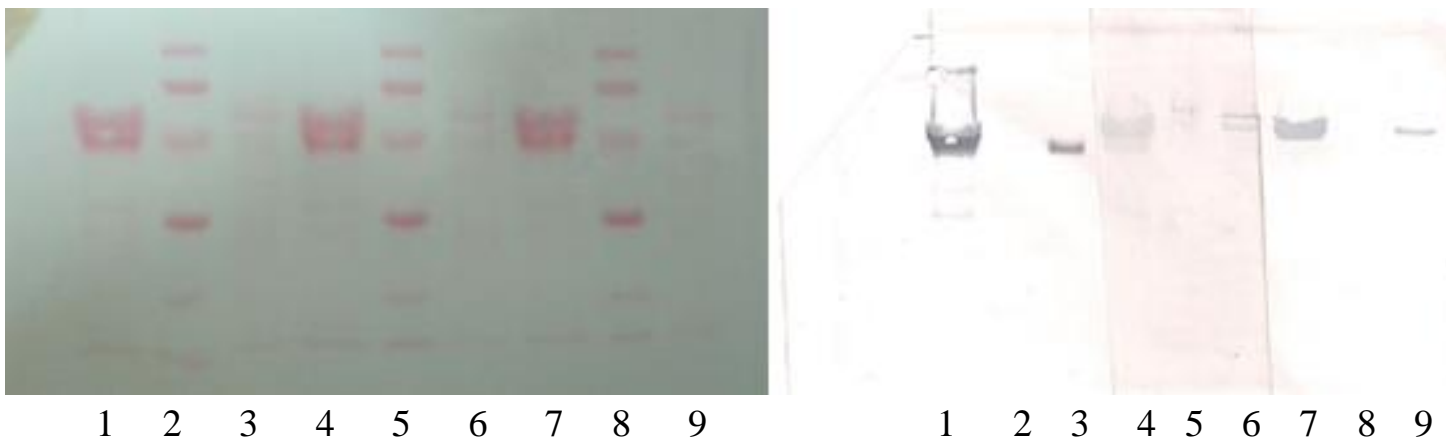

Figura 6 - Membrana de nitrocelulose corada com Ponceau (à esquerda) e Western Blot revelado com anti-PspA94 (caneletas 1-3), com anti-extrato total de pneumococo (caneletas

4-6) e com anti-PdT (caneletas 7-8). 1, 4 e 7: eluição Phenyl F2 2, 5 e 8: padrão de peso molecular $(97,66,45,30$ e $20 \mathrm{kDa}) ; 3,6$ e 9: clarificado com 0,10\% de CTAB

Tabela 3 - Primers desenhados para construção do híbrido com linker rígido

\begin{tabular}{|c|c|c|}
\hline \multirow{4}{*}{$\begin{array}{l}1^{\circ} \\
\text { PCR }\end{array}$} & \multirow{2}{*}{$\begin{array}{l}\text { PspA94 sem a região final de } \\
\text { prolina + trecho do linker }\end{array}$} & 5' TAA CCA TGG ATG GAA GCG CCC GTA GCT A 3' \\
\hline & & $\begin{array}{l}\text { 5' TTC TTT AGC TGC AGC TTC TTT AGC TGC AGC TTC TGC TGG } \\
\text { AGC TGG AGC TGG 3' }\end{array}$ \\
\hline & \multirow[b]{2}{*}{ PdT + trecho do linker } & 5' CTC GAG GTC ATT TTC TAC CTT ATC CTC TAC CTG A 3' \\
\hline & & $\begin{array}{l}\text { 5' GCT AAA GAA GCT GCA GCT AAA GAA GCT GCA GCT AAA } \\
\text { GCT ATG GCA AAT AAA GCA GTA AAT GAC TTT ATA CTA GC 3' }\end{array}$ \\
\hline \multirow{2}{*}{$\begin{array}{l}2^{\circ} \\
\mathrm{PCR}\end{array}$} & \multirow{2}{*}{$\begin{array}{l}\text { Amplificação do híbrido } \\
\text { com linker }\end{array}$} & 5’ TAA CCA TGG ATG GAA GCG CCC GTA GCT A 3’' \\
\hline & & 5' CTC GAG GTC ATT TTC TAC CTT ATC CTC TAC CTG A 3' \\
\hline
\end{tabular}

\section{CONCLUSÃO}

A proteína híbrida PspA94-PdT sem espaçador não apresentou estabilidade suficiente para ser produzida e purificada em larga escala. Com a finalidade de melhorar a estabilidade do híbrido e torná-lo passível de ser empregado em uma vacina pneumocócica, estão sendo elaboradas novas construções com espaçadores entre as duas proteínas.

\section{REFERÊNCIAS}

ARAI, R., UEDA, H., KITAYAMA, A., KAMIYA N., NAGAMUNE, T. Design of the linkers which effectively separate domains of a bifunctional fusion protein. Protein engineering v. 14 no. 8, p. 529-532, 2001.

ARAI, R.; WRIGGERS, W.; NISHIKAWA Y.; NAGAMUNE, T.; FUJISAWA, T. Conformations of Variably Linked Chimeric Proteins Evaluated by Synchrotron X-ray SmallAngle Scattering. PROTEINS: Structure, Function, and Bioinformatics v. 57, P.829-838, 2004.

BERRY, A. M.; ALEXANDER, J. E.; MITCHELL, T. J.; ANDREW, P. W.; HANSMAN, D.; PATON, J. C. Effect of defined point mutations in the pneumolysin gene on the virulence of Streptococcus pneumonia. Infect. Immun. v. 63(5):1969, 1995.

CARVALHO, R. Jr., CABRERA-CRESPO, J., TANIZAKI, M. M.. GONÇALVES, V. M. Development of production and purification processes of recombinant fragment of 
pneumococcal surface protein A in Escherichia coli using different carbon sources and chromatography sequences Appl Microbiol Biotechnol v. 94, p.683-694, 2012.

CHEN, X.; ZARO, J. L.; SHEN, W. Fusion protein linkers: Property, design and functionality. Advanced Drug Delivery Reviews v. 65, p. 1357-1369, 2013.

CHICHILI, V. P. R.; KUMAR, V.; SIVARAMAN, J. Linkers in the structural biology of protein-protein interactions. Protein Science v. 22, p.153-167 2012, 2013.

FIGUEIREDO D. B., ZANARDO R. T., KRASCHOWETZ S., CABRERA-CRESPO J., GONÇALVES V. M. Development of a purification method for pneumococcal surface protein A from clade 4 (PspA4). XV RCA do Instituto Butantan, 2013.

GONÇALVES, V. M.; TAKAGI, M.; LIMA, R. B.; MASSALDI, H.; GIORDANO, R. C.; TANIZAKI, M. M. Purification of capsular polysaccharide from Streptococcus pneumoniae serotype $23 \mathrm{~F}$ by a procedure suitable for scale-up. Biotechnol. Appl. Biochem. v. 37, p. 283-287, 2003.

GOUlART, C. SILVA, T. R.; RODRIGUEZ, D.; POLITANO, V. R.; LEITE, L. C. C.; DARRIEUX, M. Characterization of Protective Immune Responses Induced by Pneumococcal Surface Protein A in Fusion with Pneumolysin Derivatives. PLoS ONE v.8(3): e59605, 2013

HOA, S. N..; HUNT, H. D., HORTON, R. M, PULLEN, J. K.; PEASEA, L. R. Sitedirected mutagenesis by overlap extension using the polymerase chain reaction. Gene v. 77, p.51-59, 1989.

LEE, M.; BANG, K.; KWON, H.; CHO, S. Enhanced antibacterial activity of an attacincoleoptericin hybrid protein fused with a helical linker. Mol Biol Rep v. 40, p. 3953-3960, 2013.

LOWRY, O. H.; ROSENBROUGH, N. J.; FARR, R. H. Protein measurement with Folin phenol reagent. J. Biol. Chem., v.193, p.265-275, 1951.

MORENO, A.T.; OLIVEIRA, M. L. S.; FERREIRA, D. M., HO, P. L.; DARRIEUX, M.; LEIE, L. C. C.; FERREIRA Jr, J. M. C.; PIMENTA, F. C.; ANDRADE, A. L. S. S.; MIYAJI, E. N. Immunization of mice with single PspA fragemnts induces antibodies capable of mediting complemente deposition on diferente pneumococcal strains and cross-protection. Clin. Vaccine. Immunol. v. 17(3), p. 439-446, 2010.

NEW ENGLAND BIOLABS Tm calculator. Disponível em: https://www.neb.com/toolsand-resources/interactive-tools/tm-calculator. Acessado em abril de 2014.

WORLD HEALTH ORGANIZATION. Pneumococcal conjugate vaccine for childhood immunization WHO position paper. Weekly Epidemiological Record, v. 82 (12), p.93-104, 2007. 